\title{
Diseño de un bioreactor tipo UASB para el tratamiento de lixiviados provenientes de residuos urbanos
}

\section{Design of a UASB reactor for the treatment of landfill domestic waste leachate}

Fabián Ernesto Arias Arias ${ }^{1}$, Edison Geovanny Amaguaya Shagñay. ${ }^{2}$, Luis Santiago Carrera Almendáriz . ${ }^{3} \&$ Adrián Alejandro Rodríguez Pinos. ${ }^{4}$

Recibido: 13-04-2020 / Revisado: 17-05-2020 /Aceptado: 20-06-2020/ Publicado: 23-07-2020

\begin{abstract}
.
DOI: https://doi.org/10.33262/cienciadigital.v4i3.1306

A wastewater treatment system was designed for leachate degradation; the main components of the system were UASB reactors. Degradation was performed in a pilot plant reactor which required 35 days to reach an optimal temperature between 35 and $45^{\circ} \mathrm{C}$. Moreover, $\mathrm{pH}$ was maintained between 8,3 and 8,77. The chloride content increased from 2013,56 to 2902,17 $\mathrm{mg} / \mathrm{L}$ and alkalinity varied from $4100 \mathrm{mg} / \mathrm{L}$ to $5546,67 \mathrm{mg} / \mathrm{L}$. Meanwhile, ammoniacal nitrogen, biological oxygen demand and chemical oxygen demand contents decrease by $86,30 \%, 83,73 \%$, and $74,97 \%$, respectively. After 5 days of treatment, further degradation in the reactor was not significant, therefore, this time period was established as a maximum prior to recirculation. Based on these results, the treatment system was designed for a leachate capacity of $56,75 \mathrm{~m}^{3} /$ day which would be transported by a pump of $1 / 2 \mathrm{hp}$ and $110 \mathrm{~V}$ with a flow of 5-25 L/min. In addition, the leachate would be treated in 4 UASB reactors of 17,64 $\mathrm{m}^{3}$ and $321,05 \mathrm{~kg}$ of capacity each; the feed and products of these reactors would be stored in tanks of $62,40 \mathrm{~m}^{3}$.
\end{abstract}

Keywords: UASB, leachate, wastewater, environment.

1 University of Calabria, Department of Environmental and Chemical Engineering, Calabria, Italia.. fabianariasarias@gmail.com

${ }^{2}$ Escuela Superior Politécnica de Chimborazo, Facultad de Ciencias. Riobamba, Ecuador. @espoch.edu.ec. edigeovanny_94@yahoo.com

3 Escuela Superior Politécnica de Chimborazo, Facultad de Ciencias. Riobamba, Ecuador. luissantiago.carrera@espoch.edu.ec

4 Escuela Superior Politécnica de Chimborazo, Facultad de Ciencias. Riobamba, Ecuador. adrian.rodriguez@espoch.edu.ec 


\section{Resumen.}

El presente estudio tuvo por objetivo diseñar un sistema de tratamiento en base a reactores tipo UASB para degradar lixiviados en rellenos sanitarios. Previo al diseño, se realizaron pruebas en un reactor a escala piloto en donde se obtuvieron las condiciones óptimas para el tratamiento y se observó la degradación del lixiviado. Se determinó que el reactor requiere 35 días para alcanzar el rango de temperatura óptimo de $35-45^{\circ} \mathrm{C}$ y una vez alcanzada esta temperatura requiere de recirculación cada 5 días. Con respecto a los parámetros del lixiviado, se pudo notar un $\mathrm{pH}=8,3-8,77$, el contenido de cloruros varió entre 2013,56 mg/L$2902,17 \mathrm{mg} / \mathrm{L}$, la alcalinidad tuvo valores de $4100 \mathrm{mg} / \mathrm{L}-5546,67 \mathrm{mg} / \mathrm{L}$, el nitrógeno amoniacal alcanzó una reducción del 86,30\% mientras que el DBO y el DQO se degradaron en un $83,73 \%$ y $74,97 \%$, respectivamente. En base a estos resultados, se diseñó un sistema de tratamiento con capacidad de tratar caudales de $56,75 \mathrm{~m}^{3} /$ día; se propuso una bomba de $1 / 2 \mathrm{hp}$ y $110 \mathrm{~V}$ que puede manejar un flujo volumétrico de $5-25 \mathrm{~L} / \mathrm{min}$. Además, se diseñaron tanques de almacenamiento con un volumen de $62,40 \mathrm{~m}^{3}$. Finalmente, se consideraron 4 reactores UASB con un volumen de $17,64 \mathrm{~m}^{3}$ capaces de manejar un flujo másico de lixiviado de $321,05 \mathrm{~kg}$.

Palabras claves: UASB, lixiviados, aguas residuales, ambiente.

\section{Introducción.}

El tratamiento de residuos es considerablemente uno de los mayores problemas que enfrentan los países en desarrollo. En general, muchos de los residuos sólidos sin una previa clasificación son depositados en rellenos sanitarios que con el pasar del tiempo pueden generar lixiviados debido a su descomposición o por el contacto de los residuos con agua filtrada por el suelo (Contreras y Suarez, 2006). Los lixiviados se consideran como aguas residuales de compleja composición que pueden causar afectación al ambiente y a los seres vivos por su toxicidad.

Los lixiviados pueden ser tratados mediante varios procesos siendo el tratamiento biológico anaeróbico una alternativa debido a su bajo costo en términos de energía e infraestructura. Además, una de las ventajas más grandes de este tratamiento es que se reduce la cantidad de lodos en comparación con un tratamiento de aguas convencional lo cual permite eliminar las unidades de digestión de lodos. A pesar de la reducción de lodos, estos últimos pueden ser utilizados como una fuente de energía no convencional. (Torres et al. 2005) (Malina y Pohland, 1992). Los tratamientos biológicos anaeróbicos son utilizados para lixiviados que tengan una relación mayor a 0,4 entre la demanda bioquímica de oxígeno (DBO) y demanda química de oxígeno (DQO) (Martínez López et al. 2014). Generalmente, los lixiviados pueden ser descargados a los cuerpos de agua al disminuir DBO, DQO y la concentración de amonio (Kettunen et al.1996).

El reactor de tipo UASB (upflow anaerobic sludge blanker o reactor anaeróbico de flujo ascendente) es utilizado para el tratamiento anaeróbico de lixiviados. De acuerdo a Kettunnen y 
Rintala (1998), mencionan que los tratamientos en reactores UASB son utilizados cuando los valores de DQO son mayores a $800 \mathrm{mg} / \mathrm{L}$ y cuando la relación DBO/DQO se encuentra entre 0,3 - 0,7. En ocasiones los reactores UASB son complementados con tratamientos de lodos activados, filtros percoladores o lagunas.

El reactor de flujo ascendente consiste en bacterias en forma de gránulos que se desarrollan en un lodo biológicamente activo para degradar materia orgánica. La densidad de las bacterias asociadas en gránulos permite que las mismas sedimenten en el digestor y así la biomasa permanece en el reactor sin necesidad de soporte adicional (Kennedy y Lentz, 2000). En muchos casos se prefiere una degradación anaeróbica debido a que existen productos secundarios como el metano y el lodo biológico tiene una tasa de crecimiento baja.

Los principales parámetros a considerar en los reactores UASB son la temperatura y el $\mathrm{pH}$ del medio. Al tratar con sistemas que se encuentran a temperatura ambiente, la población bacteriana que se encuentra es de tipo mesófila y se desarrolla óptimamente a temperaturas de 15 a $27^{\circ} \mathrm{C}$ en un ambiente propicio para el desarrollo metabólico de los microorganismos y una generación adecuada de biomasa (Salazar Gámez y Saavedra Antolínez, 2009).

En el caso del pH, es importante mantener un nivel óptimo por dos principales razones. Primero, las reacciones químicas que se producen en el reactor pueden ser favorecidas dependiendo del $\mathrm{pH}$ del sustrato. Segundo, los microorganismos se desarrollan favorablemente en ambientes de $\mathrm{pH}$ neutro (Madigan et al. 2010). Sin embargo, existen estudios que han conseguido un mejor tratamiento de lixiviados en rangos de $\mathrm{pH}$ de 5,5-8,4 (Parra-Orobio et al. 2014).

Los lixiviados que se generan en su relleno sanitario son llevados hacia un depósito en el cual son tratados biológicamente de forma anaerobia. Sin embargo, el tratamiento no es lo suficientemente óptimo para poder reincorporar el agua a cuerpos hídricos, lo cual en algún momento puede causar problemas de almacenamiento. Por esta razón, es fundamental realizar un tratamiento biológico adecuado para que las aguas residuales tratadas puedan cumplir con las normas ambientales establecidas en la reforma al TULSMA (Texto Unificado de Legislación Secundaria del Medio Ambiente). La presente investigación está orientado al diseño de un sistema de tratamiento UASB para los lixiviados producidos rellenos sanitarios de tal forma que las propiedades físico-químicas y biológicas de las aguas residuales se encuentren dentro de los parámetros establecidos en la norma ambiental nacional.

\section{Metodología}

Los lixiviados utilizados para esta investigación fueron obtenidos de un relleno sanitario. Los lodos activados utilizados como fuente de microorganismos provienen de una planta de tratamiento de aguas residuales específicamente de las eras de secado.

\section{Muestreo y caracterización de lixiviados.}


Se tomaron 40 litros de lixiviado en el periodo de mayor actividad del relleno sanitario (7 am-7 pm). Esta cantidad de lixiviado fue recolectada mediante un muestreo compuesto previo a su caída en la piscina almacenadora de lixiviados. Los volúmenes de cada alícuota para posteriormente obtener los $40 \mathrm{~L}$ de la muestra total se obtuvieron mediante la Ec.1. En el caso de los lodos activados, se tomaron $5 \mathrm{~kg}$ de los lodos en exceso de un reactor Imhoff por muestreo simple.

$$
\begin{array}{cc}
V i=\frac{V \times Q i}{n \times Q p} \quad \text { Ec. } \mathbf{1} \\
\mathbf{V i}=\text { volumen de cada alícuota } \\
\mathbf{V}=\text { volumen de la muestra total } \\
\mathbf{Q i}=\text { caudal instantáneo de cada muestra } \\
\mathbf{Q p}=\text { caudal promedio durante el muestreo } \\
\mathbf{n}=\text { número de muestras tomadas }
\end{array}
$$

Los principales parámetros para controlar los lixiviados se muestran en la Tabla 1. El control de estas propiedades implica el óptimo funcionamiento del reactor y la posibilidad de descargar el efluente hacia cuerpos hídricos.

Tabla 1. Parámetros físico-químicos de lixiviados.

\begin{tabular}{lcc}
\hline Parámetro. & Tipo de método. & $\begin{array}{c}\text { Códigos APHA- } \\
\text { AWWA }\end{array}$ \\
\hline Cloruros & Volumétrico - & $4500 \mathrm{Cl}-\mathrm{B}$ \\
Alcalinidad & Argentométrico & $2320-\mathrm{B}$ \\
Nitrógeno & Volumétrico & $4500 \mathrm{NH} 4-\mathrm{C}$ \\
amoniacal & Colorimétrico - Nessler & $5210-\mathrm{B}$ \\
DBO & Oxido Reducción & $5220-\mathrm{D}$ \\
DQO & Oxido Reducción & $4500 \mathrm{~h}-\mathrm{B}$ \\
pH & Potenciométrico & $2550-\mathrm{B}$ \\
Temperatura & En campo & \\
\hline
\end{tabular}

Fuente: Amaguaya Shagñay (2019). Adaptada de Standard Methods for the Examination of Water and Wastewater [Standard Methods], 2020.

\section{Condiciones de evaluación y diseño del reactor.}

El sistema UASB para el tratamiento de lixiviados en el relleno sanitario fue diseñado a partir de valores de referencia obtenidos en un reactor piloto UASB en el cual a su vez se trató el lixiviado; los valores de referencia se encuentran listados en la Tabla 2. El tratamiento del lixiviado en el reactor piloto comenzó por la mezcla de los lodos activados del reactor Imhoff con estiércol de ganado en una relación 2 a 1 para la mejora de la carga bacteriana (Orozco et al. 2014). Luego, la mezcla se secó por $24 \mathrm{~h}$ a una temperatura de $40^{\circ} \mathrm{C}$ y posteriormente se introdujo al reactor de tal forma que cubra el $70 \%$ del volumen efectivo del reactor. 


\section{C) Ciencia

Los sensores de temperatura del reactor y de la potencia de la bomba peristáltica fueron controlados por un sistema arduino el cual es un sistema de código libre que permite controlar diferente variables en un proceso. Una vez alcanzada la temperatura de $30-45^{\circ} \mathrm{C}$, se consideró como iniciado el tratamiento de lixiviado; las muestras fueron analizadas mediante dos metodologías. La primera forma fue el análisis luego de 24 horas de alcanzar la temperatura óptima y la segunda forma fue mediante recirculación cada 24 horas a partir del segundo día por un periodo total de 7 días.

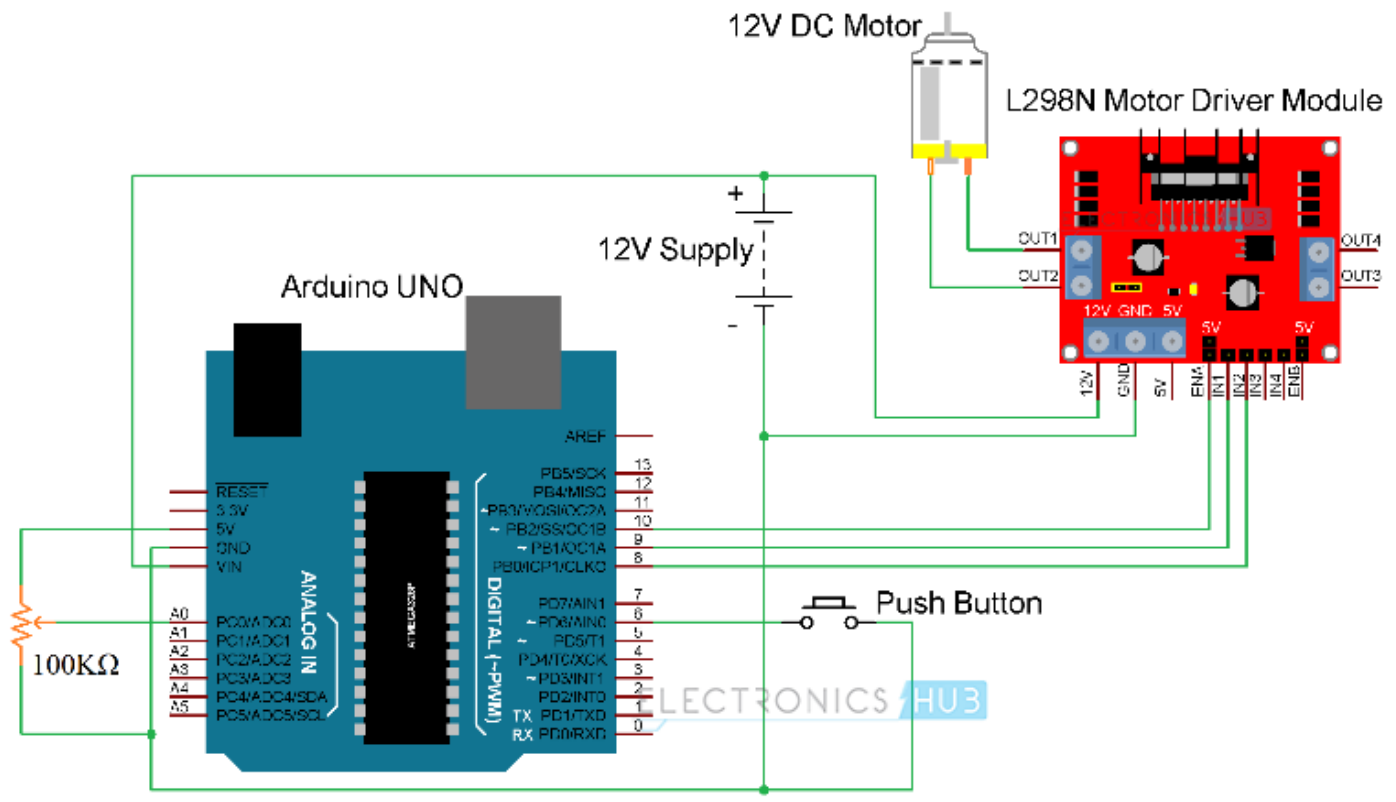

Figura 1. Diseño de conexión Arduino al chip alimentador de la bomba.

Fuente: Amaguaya Shagñay (2019)

Tabla 2. Valores de referencia para diseño

\begin{tabular}{|c|c|c|c|}
\hline Parámetro. & Símbolo & Rango & $\begin{array}{l}\text { Unidad } \\
\text { medida }\end{array}$ \\
\hline Demanda Química de Oxígeno & DQO & Valor de caracterización. & $\mathrm{kg} / \mathrm{m}^{3} \mathrm{~d}$ \\
\hline Tiempo de residencia hidráulico & TRH & $0,7-1$ & día \\
\hline Diámetro & $\mathrm{D}$ & $\begin{array}{l}\text { De acuerdo al material a } \\
\text { usar }\end{array}$ & $\mathrm{cm}$ \\
\hline Caudal & Q & 7 & $\mathrm{~mL} / \mathrm{min}$ \\
\hline Ancho mínimo interno de la campana & $\mathrm{H}_{\mathrm{T}}$ & 2 & $\mathrm{~cm}$ \\
\hline $\begin{array}{l}\text { Altura tope del separador GLS sobre la } \\
\text { superficie del liquido }\end{array}$ & $\mathrm{L}_{\mathrm{T}}$ & 2 & $\mathrm{~cm}$ \\
\hline Angulo de inclinación de la campana. & $\alpha$ & 60 & $\circ$ \\
\hline Angulo de inclinación de los deflectores & $\beta$ & 45 & $\circ$ \\
\hline
\end{tabular}

Fuente: Amaguaya Shagñay (2019). Adaptada de Lettiga et al. (1980). 
La temperatura se controló constantemente para que no exista ninguna variación dentro del rango óptimo. El pH se lo analizó cada dos días a partir del primer día que se colocaron los lodos activados en el reactor en la mitad del lodo y en la sección superior del reactor. Con respecto al DBO, DQO y nitrógeno amoniacal, los análisis se realizaron por 7 días a partir de haber alcanzado la temperatura óptima para comprobar que el reactor se encuentre degradando el lixiviado. Simultáneamente, los valores de estos tres parámetros se compararon en forma de porcentaje con los parámetros del lixiviado sin tratar.

Para el diseño del sistema UASB, se utilizaron las ecuaciones de diseño de reactores UASB mostradas en la Tabla 3 y se siguió una metodología específica que partió de la determinación del caudal de lixiviados en un vertedero triangular ubicado en el relleno sanitario por 7 semanas. Para la determinación del caudal, primero se midió la altura del fluido $(\mathrm{H})$, segundo se aplicó la Ec. 2 y tercero se manipularon los datos para determinar un caudal promedio. Una vez obtenido el caudal promedio, a partir de los parámetros físico, químicos y biológicos del lixiviado tratado en el reactor piloto se determinó el tiempo de recirculación del reactor y el tiempo de residencia hidráulico óptimo.

Tabla 3. Ecuaciones de diseño.

\begin{tabular}{|l|l|l|}
\hline Nombre & Símbolo & Ecuación \\
\hline Caudal del lixiviado & $\mathrm{Q}$ & $Q=1,4 x H^{\frac{5}{2}} \quad$ Ec. 2 \\
\hline Volumen del reactor & $\mathrm{V}_{\mathrm{R}}$ & $V_{R}=T R H \cdot Q$ Ec.3 \\
\hline Área del reactor & $\mathrm{A}_{\mathrm{R}}$ & $A_{R}=\frac{\pi \cdot D^{2}}{4} \quad$ Ec. $\mathbf{4}$ \\
\hline Radio del reactor & $\mathrm{R}_{\mathrm{R}}$ & $R_{R}=\frac{D}{2} \quad$ Ec. $\mathbf{5}$ \\
\hline Altura efectiva del reactor & $\mathrm{L}$ & $L=\frac{4 . V_{R}}{\pi \cdot D^{2}}$ \\
\hline Carga hidráulica & Ec. 6 \\
\hline Flujo másico & $\mathrm{C}_{\mathrm{H}}$ & $C_{H}=\frac{Q}{A_{R}}$ \\
\hline Velocidad de Flujo en la campana $\mathbf{7}$ \\
\hline Área de abertura & $\mathrm{F}$ & $F=V_{R} \cdot D Q O$ Ec. 8 \\
\hline Área de sección transversal de la campana & $\mathrm{A}_{\mathrm{C}}$ & $A_{C}=A_{R}-A \quad$ Ec. 11 \\
\hline Radio mayor de la campana & $\mathrm{R}_{\mathrm{C}}$ & $R_{C}=\sqrt{\frac{A_{C}}{\pi}} \quad$ Ec. 12 \\
\hline Ancho de la abertura & & $V_{f}=4 C_{H}$ \\
\hline
\end{tabular}




\begin{tabular}{|l|l|l|}
\hline Ancho de la campana & $\mathrm{W}_{\mathrm{G}}$ & $\begin{array}{l}W_{G}=R_{R}-W_{A}-0,5\left(H_{T}\right) \\
\text { Ec. } 14\end{array}$ \\
\hline Altura de la campana & & $H_{g}=W_{G} \cdot \operatorname{tg} \alpha \quad$ Ec. 15 \\
\hline Traslapo & $\mathrm{H}_{\mathrm{g}}$ & $T_{V}=1,5\left(W_{A}\right) \quad$ Ec. 16 \\
\hline Ancho de los deflectores & $\mathrm{T}_{\mathrm{V}}$ & $W_{D}=T_{V}+W_{A} \quad$ Ec. 17 \\
\hline Longitud de los deflectores & $\mathrm{W}_{\mathrm{D}}$ & $L_{D}=2 W_{D} \operatorname{tg} \beta \quad$ Ec. 18 \\
\hline
\end{tabular}

Fuente: Amaguaya Shagñay (2019). Adaptada de Lettiga et al. (1980).

\section{Resultados}

Utilizando la Ec.2, y con una altura de fluido que varía por cada día, se obtuvo un caudal inicial (Qi) de 785,83 L/h. Para el caudal promedio, se ocupó el dato del día anterior que fue Qp de 970,41 L/h. En base a estos datos, se empleó la Ec.1 para la obtención del volumen de las alícuotas el cual fue de 2,7 L. Esto implica la recolección de 12 alícuotas de 2,7 L de lixiviado.

El diseño del reactor piloto parte de los datos de referencia localizados en la tabla 2. Los valores que se modificaron fueron un TRH=1 dìa y el DQO del lixiviado sin tratar que fue de $18,2 \mathrm{Kg} / \mathrm{m}^{3} \mathrm{~d}$. En base a estos valores, se realizaron los cálculos correspondientes de las ecuaciones mostradas en la tabla 3 para obtener los valores para el diseño del reactor piloto que se muestran en la tabla 4.

Tabla 4. Valores para el diseño del reactor piloto.

\begin{tabular}{lccc}
\hline Nombre & Símbolo & Valor & Unidad \\
\hline Volumen del reactor & $\mathrm{V}_{\mathrm{R}}$ & 10080 & $\mathrm{~mL}$ \\
Área del reactor & $\mathrm{A}_{\mathrm{R}}$ & 74 & $\mathrm{~cm}^{2}$ \\
Altura efectiva del reactor & $\mathrm{L}$ & 136,4 & $\mathrm{~cm}$ \\
Carga hidráulica & $\mathrm{C}_{\mathrm{H}}$ & 0,054 & $\mathrm{~m} / \mathrm{h}$ \\
Flujo másico & $\mathrm{F}$ & 0,18 & $\mathrm{~kg} /$ día \\
Velocidad de Flujo en la campana & $\mathrm{V}_{\mathrm{f}}$ & 0,378 & $\mathrm{~cm} / \mathrm{min}$ \\
Área de abertura & $\mathrm{A}$ & 18,52 & $\mathrm{~cm}^{2}$ \\
Área de sección transversal de la campana & $\mathrm{A}_{\mathrm{C}}$ & 55,48 & $\mathrm{~cm}^{2}$ \\
Ancho de la abertura & $\mathrm{W}_{\mathrm{A}}$ & 0,65 & $\mathrm{~cm}$ \\
Ancho de la campana & $\mathrm{W}_{\mathrm{G}}$ & 3,2 & $\mathrm{~cm}$ \\
Altura de la campana & $\mathrm{H}_{\mathrm{g}}$ & 5,5 & $\mathrm{~cm}$ \\
Traslapo & $\mathrm{T}_{\mathrm{V}}$ & 0,975 & $\mathrm{~cm}$ \\
Ancho de los deflectores & $\mathrm{W}_{\mathrm{D}}$ & 1,65 & $\mathrm{~cm}$ \\
Longitud de los deflectores & $\mathrm{L}_{\mathrm{D}}$ & 3,3 & $\mathrm{~cm}$ \\
\hline
\end{tabular}

Fuente: Amaguaya Shagñay (2019). 
Una vez construido el reactor piloto con los valores de diseño respectivos, se procedió a realizar pruebas de tratamiento del lixiviado. Los parámetros del lixiviado sin tratar se muestran en la Tabla 5. Es importante notar que el DQO ha alcanzado un valor de $24800 \mathrm{mg} / \mathrm{L}$ debido a los frecuentes cambios meteorológicos de la zona y la constante variación de la composición de los residuos en el relleno sanitario (Caicedo Messa, 2006).

Tabla 5. Resultados de la caracterización inicial del lixiviado.

\begin{tabular}{lcc}
\hline \multicolumn{1}{c}{ Parámetro. } & Valor & Unidad \\
\hline Cloruros & 11438 & $\mathrm{mg} / \mathrm{L}$ \\
Alcalinidad & 20666 & $\mathrm{mg} / \mathrm{L}$ \\
Nitrógeno amoniacal & 2050 & $\mathrm{mg} / \mathrm{L}$ \\
DBO & 15853 & $\mathrm{mg} / \mathrm{L}$ \\
DQO & 24800 & $\mathrm{mg} / \mathrm{L}$ \\
pH & 8,3 & \\
Temperatura & 14,5 & ${ }^{\circ} \mathrm{C}$ \\
\hline
\end{tabular}

Fuente: Amaguaya Shagñay (2019).

La temperatura del lodo indica la iniciación del proceso de degradación del lixiviado. El reactor tomó la cantidad de 35 días para alcanzar la temperatura óptima de $35^{\circ} \mathrm{C}$ alcanzando inclusive temperaturas de $45^{\circ} \mathrm{C}$. Una vez alcanzada la temperatura adecuada, luego de 24 horas se tomó la primera muestra para comprobar los cambios en sus parámetros; esto se continuó realizando por 6 días para un total de 7 días de tratamiento. Posterior a este periodo de tiempo se debe recircular el lixiviado; es decir se debe incorporar una nueva alimentación al reactor UASB con alta carga orgánica.

Los datos de los análisis realizados durante los 7 días de tratamiento se muestran en la Tabla 6. Los parámetros de control fueron cloruros, alcalinidad y $\mathrm{pH}$. Se puede notar que no existe un aumento significativo en la cantidad de cloruros durante el tratamiento por lo que se puede concluir que no se afectó el crecimiento bacteriano.

Con respecto a la alcalinidad, existe una reducción significativa lo cual puede indicar un aumento de la concentración de ácidos grasos volátiles que puede inhibir el crecimiento bacteriano en el sistema (Orozco et al. 2014). Finalmente, el pH se mantuvo entre los valores 8,3 y 8,77 que está relativamente dentro del rango adecuado para el crecimiento bacteriano $(5,5-8,5)$ (Parra-Orobio et al. 2014).

Los parámetros que indican una degradación del lixiviado son nitrógeno amoniacal, DBO y DQO. Para estos parámetros en la tabla 6, se indican los valores en cada día de tratamiento acompañados entre paréntesis por los porcentajes de variación. 
Es importante notar que los valores de estos estos tres parámetros a partir del quinto día no poseen un cambio significativo lo cual puede indicar que se requiere alimentar al reactor con una nueva muestra de lixiviado. Con respecto al nitrógeno amoniacal se puede notar que en el quinto día existe una reducción del $85,61 \%$ lo cual indica la conversión de compuestos orgánicos a compuestos inorgánicos.

En el caso del DBO, existe una reducción en el quinto día del $82,51 \%$ lo que indica efectivamente la reducción de la carga orgánica del lixiviado mediante la acción de las bacterias. Finalmente, el DQO muestra una degradación al quinto día del 75,27\%.

Tabla 6. Resultados de los análisis según el día de tratamiento.

\begin{tabular}{|c|c|c|c|c|c|c|c|}
\hline \multirow{2}{*}{ Parámetro } & \multicolumn{7}{|l|}{ Día } \\
\hline & 1 & 2 & 3 & 4 & 5 & 6 & 7 \\
\hline Cloruros $(\mathrm{mg} / \mathrm{L})$ & 2599,67 & 2297,16 & 2297,16 & 2902,17 & 2316,07 & 2013,56 & 2571,31 \\
\hline $\begin{array}{l}\text { Alcalinidad } \\
(\mathrm{mg} / \mathrm{L})\end{array}$ & 5546,67 & 4733,33 & 4733,33 & 4300 & 4100 & 4266,67 & 4200 \\
\hline $\mathrm{pH}$ & 8,4 & 8,45 & 8,45 & 8,4 & 8,3 & 8,4 & 8,77 \\
\hline $\begin{array}{l}\text { Nitrógeno } \\
\text { amoniacal (mg/L) }\end{array}$ & $\begin{array}{l}1429,17 \\
(30,28 \%)\end{array}$ & $\begin{array}{l}461,67 \\
(77,48 \%)\end{array}$ & $\begin{array}{l}461,67 \\
(79,15 \%)\end{array}$ & $\begin{array}{l}335 \\
(83,66 \%)\end{array}$ & $\begin{array}{l}295 \\
(85,61 \%)\end{array}$ & $\begin{array}{l}283,33 \\
(86,18 \%)\end{array}$ & $\begin{array}{l}280 \\
(86,30 \%)\end{array}$ \\
\hline DBO & 4473,33 & 3766,67 & 3766,67 & 2873,33 & 2773,33 & 1866,67 & 2580 \\
\hline$(\mathrm{mg} / \mathrm{L})$ & $(71,78 \%)$ & $(76,24 \%)$ & $(75,74 \%)$ & $(81,88 \%)$ & $(82,51 \%)$ & $(88,23 \%)$ & $(83,73 \%)$ \\
\hline DQO & 10280 & 9433,33 & 9433,33 & 7893,33 & 6100 & 5913,33 & 6173,33 \\
\hline$(\mathrm{mg} / \mathrm{L})$ & $(58,32 \%)$ & $(61,76 \%)$ & $(63,73 \%)$ & $(68,00 \%)$ & $(75,27 \%)$ & $(76,03 \%)$ & $(74,97 \%)$ \\
\hline
\end{tabular}

Fuente: Amaguaya Shagñay (2019).

Para el diseño del sistema de tratamiento de los lixiviados a escala del relleno sanitario se determinó un caudal máximo de $56,75 \mathrm{~m}^{3} /$ día, caudal mínimo de $12,87 \mathrm{~m}^{3} /$ día y un caudal promedio de 19,87 $\mathrm{m}^{3} /$ día. Se tomó en cuenta los parámetros mostrados en la tabla 2 y considerando un $\mathrm{TRH}=0,7$ días, $\mathrm{DQO}=18,2 \mathrm{~kg} / \mathrm{m}^{3} \mathrm{~d}$, caudal medido $\left(\mathrm{Qm}=56,75 \mathrm{~m}^{3} /\right.$ día $)$ y un caudal bomba $\left(\mathrm{Q}=25,2 \mathrm{~m}^{3} /\right.$ día $)$. Este último, se bombeará al sistema de tratamiento mediante una bomba de $1 / 2 \mathrm{hp}$ y $110 \mathrm{~V}$ que puede manejar un flujo volumétrico de $5-25 \mathrm{~L} / \mathrm{min}$.

Debido a que el reactor a partir del quinto día no muestra cambios significativos en el lixiviado, se necesitan dimensionar tanques de almacenamiento de lixiviados que puedan contener el caudal máximo. Dos tanques rectangulares con una capacidad total del doble del caudal máximo y con un 
factor de seguridad del $10 \%$ con respecto al almacenamiento se diseñaron con las siguientes dimensiones: Volumen tanque $=62,40 \mathrm{~m}^{3}$, Área tanque $=41,62 \mathrm{~m}^{2}$, Longitud base $=4,6 \mathrm{~m}$, Longitud de lados $=9,2 \mathrm{~m}$. Además, se diseñaron dos tanques rectangulares para la alimentación y el producto del reactor UASB cada uno con las siguientes dimensiones: Volumen tanque $=27,72 \mathrm{~m}^{3}$, Área tanque $=9,24 \mathrm{~m}^{2}$, Longitud base $=2,15 \mathrm{~m}$, Longitud de lados $=4,3 \mathrm{~m}$. Todos los tanques tendrán un grosor de muro de $20 \mathrm{~cm}$.

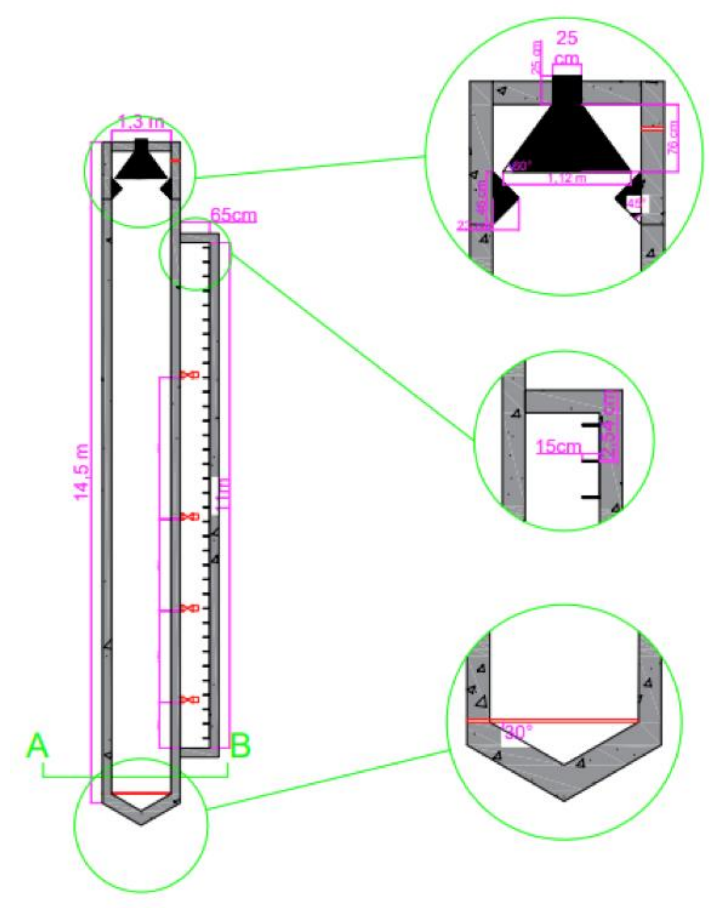

Figura 2. Diseño del reactor UASB para el tratamiento de lixivados provenientes de rellenos sanitarios.

Fuente: Amaguaya Shagñay (2019).

Finalmente, para que los reactores abastezcan el caudal máximo de lixiviados producidos en el relleno sanitario, se diseñaron 4 reactores de los cuales cada uno de ellos tiene una capacidad de la mitad del caudal máximo producido. Las características de los reactores diseñados se indican en la siguiente tabla.

Tabla 7. Valores para el diseño del reactor a escala de una planta de tratamiento.

\begin{tabular}{lccc}
\hline \multicolumn{1}{c}{ Nombre } & Símbolo & Valor & Unidad \\
\hline Volumen del reactor & $\mathrm{V}_{\mathrm{R}}$ & 17,64 & $\mathrm{~m}^{3}$ \\
Área del reactor & $\mathrm{A}_{\mathrm{R}}$ & 1,33 & $\mathrm{~m}^{2}$ \\
Altura efectiva del reactor & $\mathrm{L}$ & 13 & $\mathrm{~m}$ \\
Carga hidráulica & $\mathrm{C}_{\mathrm{H}}$ & 18,95 & $\mathrm{~m} / \mathrm{día}$ \\
Flujo másico & $\mathrm{F}$ & 321,05 & $\mathrm{~kg} / \mathrm{día}$ \\
Velocidad de Flujo en la campana & $\mathrm{V}_{\mathrm{f}}$ & 75,8 & $\mathrm{~m} / \mathrm{día}$
\end{tabular}




\begin{tabular}{|c|c|c|c|}
\hline Área de abertura & A & 0,33 & $\mathrm{~m}^{2}$ \\
\hline $\begin{array}{l}\text { Área de sección transversal de la } \\
\text { campana }\end{array}$ & $\mathrm{A}_{\mathrm{C}}$ & 1 & $\mathrm{~m}^{2}$ \\
\hline Radio mayor de la campana & $\mathrm{Rc}$ & 0,56 & $\mathrm{~m}$ \\
\hline Ancho de la abertura & $\mathrm{W}_{\mathrm{A}}$ & 0,09 & $\mathrm{~m}$ \\
\hline Ancho de la abertura de la campana & $\mathrm{W}_{\mathrm{G}}$ & 0,44 & $\mathrm{~m}$ \\
\hline Altura de la campana & $\mathrm{H}_{\mathrm{g}}$ & 0,76 & $\mathrm{~m}$ \\
\hline Traslapo & $\mathrm{T}_{\mathrm{V}}$ & 0,14 & $\mathrm{~m}$ \\
\hline Ancho de los deflectores & $\mathrm{W}_{\mathrm{D}}$ & 0,23 & $\mathrm{~m}$ \\
\hline Longitud de los deflectores & $\mathrm{L}_{\mathrm{D}}$ & 0,46 & $\mathrm{~m}$ \\
\hline
\end{tabular}

Fuente: Amaguaya Shagñay (2019).

\section{Conclusiones}

- Los rellenos sanitarios generan lixiviados que requieren un tratamiento adecuado para que sus líquidos residuales puedan cumplir con las normas ambientales establecidas y evitar la contaminación del medio ambiente que perjudicaría a las comunidades en el área de influencia del relleno. Todo líquido contaminante debe ser tratado antes de ser vertido en aguas superficiales o subterráneas, de tal manera que se propone a través del tratamiento biológico en biorreactores tipo UASB la remediación de estos efluentes.

- La caracterización físico-química de los lixiviados del relleno sanitario demuestran que los parámetros de concentración de nitrógeno amoniacal, DBO y DQO no cumplen con los límites permisibles según el Texto Unificado de Legislación Secundaria del Medio Ambiente (TULSMA). Sin embargo, el lixiviado analizado presenta un $\mathrm{pH}$ de 8,3 considerado eficiente para la degradación anaeróbica.

- Con un caudal inicial de $785,83 \mathrm{~L} / \mathrm{h}$ se realiza el cálculo de ingeniería y el dimensionamiento de un biorreactor tipo UASB que consta de dos tanques de almacenamiento, un tanque de alimentación para los reactores UASB, cuatro reactores UASB y un tanque de almacenamiento para el lixiviado tratado. El reactor alcanza condiciones óptimas de funcionamiento en 35 días con una temperaturas de $35-45^{\circ} \mathrm{C}$ permitiendo el crecimiento adecuado de la población bacteriana mesófila y $\mathrm{pH}$ de 8,30 . La recirculación al quinto día demostró que el reactor es capaz de disminuir los parámetros de interés hasta rango permisibles según Texto Unificado de Legislación Secundaria del Medio Ambiente (TULSMA) para la descarga del lixiviado en fuentes de agua alcanzando una concentración de nitrógeno amoniacal de 280 mg/L, DBO de 2773,33 mg/L y DQO de $6100 \mathrm{mg} / \mathrm{L}$.

- Se abren líneas de investigación futuras respecto a la optimización del proceso en función de las condiciones de operación y el estudio de la cinética de la degradación del lixiviado.

\section{Referencias bibliográficas.}

Amaguaya Shagñay, E.G. (2019). Diseño de un sistema biológico para la depuración de lixiviados generados en el relleno sanitario de Porlón [Monografía]. http://dspace.espoch.edu.ec/handle/123456789/13117 
Caicedo Messa, F.J., (2006). Diseño, construcción y arranque de un reactor U.A.S.B Piloto para el tratamiento de lixiviados. Universidad Nacional de Colombia.

Contreras, A., \& Suarez, J. (2006). Tratamiento Biológico de Lixiviados de Rellenos Sanitarios. Revista Respuestas- Universidad Francisco de Paula Santander, 11(1), 24-32.

Kennedy, K.J. \& Lentz, E.M., (2000). Treatment of landfill leachate using sequencing batch and continuous flow upflow anaerobic sludge blanket (UASB) reactors. Water Research, 34(14), 3640-3656. https://doi.org/10.1016/S0043-1354(00)00114-7

Kettunen, R.H., Hoilijoki ,T.H., Rintala, J.A., (1996). Anaerobic and sequential anaerobic-aerobic treatments of municipal landfill leachate at low temperatures. Bioresource Technoly, 58, 31-40. https://doi.org/10.1016/S0960-8524(96)00102-2

Kettunen, R.H., Rintala, J.A., (1998). Performance of an on-site UASB reactor treating leachate at low temperature. Water Research, 32(3), 537-46. https://doi.org/10.1016/S00431354(97)00319-9

Lettinga, Velsen, Van y Hobma, (1980). Use of the upflow sludge blanket (UASB) reactor concept for biological 41 wastewater treatment, especially for anaerobic treatment, 22, 699-734. https://doi.org/10.1002/bit.260220402

Madigan, M., Martinko, J.M. \& Parker, J. (2010). Brock, Biología de los Microorganismos. Prentice Hall. 457-586.

Malina J. F. and Pohland F. G. (1992) Design of Anaerobic Processes for the Treatment of Industrial and Municipal Wastes. Water Quality Management Library Volumen 7, Technomic Publishing Co. Inc., 169.

Martinez Lopez, A.G., Padron Hernandez, W., Rodriguez Bernal, O.F., Chiquito Coyotl, O., Escarola Rosas, J,M., Hernandez Lara, J.M., Elvira Hernandez, E.A., Mendez, G.A., Tinoco Magaña, J.C., \& Martinez Castillo, J. (2014). Alternativas actuales del manejo de lixiviados. Avances en Química, 9, 37-47

Orozco Gaviria, C.A., Triviño Cabrera, C.C., Manrique Losada, L., (2014) Start-up a UASB reactor for domestic wastewater treatment in Andean-Amazonian conditions. Revista Facultad de Ciencias Básicas, 10(2), 170-185.

Parra-Orobio, B.S., Torres-Lozada, P., Marmolejo-Rebellón, L.F., Cárdenas-Cleves, L.M., Vásquez-Franco, C., Torres-López, W.A., Ordóñez-Andrade, J.A. (2014). Influencia del $\mathrm{pH}$ sobre la digestión anaerobia de biorresiduos de origen municipal. Revista U.D.C.A Actualidad \& Divulgación Científica, 17 (2), 553 - 562.

Salazar Gámez, L.L., Saavedra Antolínez, I.M. (2009). Tratamiento de lixiviados, casos prácticos en diferentes temperaturas. Universidad del Norte. 
Standard Methods. (1 de julio 2020). Standard Methods for the Examination of Water and Wastewater. https://www.standardmethods.org/doi/book/10.2105/smww.2882.

Torres, P., Rodríguez, J., Barba, L., Morán, A., \& Narváez, J. (2005). Tratamiento anaerobio de lixiviados en reactores UASB. Revita Científica Ingeniería y Desarrollo, 18, 50-60.

TULSMA: Reforma Texto Unificado Legislación Secundaria Medio Ambiente, Libro VI, Anexo I (2015). 


\section{PARA CITAR EL ARTÍCULO INDEXADO.}

Arias Arias, F. E., Amaguaya Shagñay, E. G., Carrera Almendáriz, L. S., \& Rodríguez Pinos, A. A. (2020). Diseño de un bioreactor tipo UASB para el tratamiento de lixiviados provenientes de residuos urbanos. Ciencia Digital, 4(3), 138-151. https://doi.org/10.33262/cienciadigital.v4i3.1306

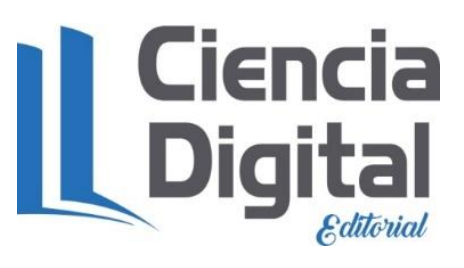

El artículo que se publica es de exclusiva responsabilidad de los autores y no necesariamente reflejan el pensamiento de la Revista Ciencia Digital.

El artículo queda en propiedad de la revista y, por tanto, su publicación parcial y/o total en otro medio tiene que ser autorizado por el director de la Revista Ciencia Digital.
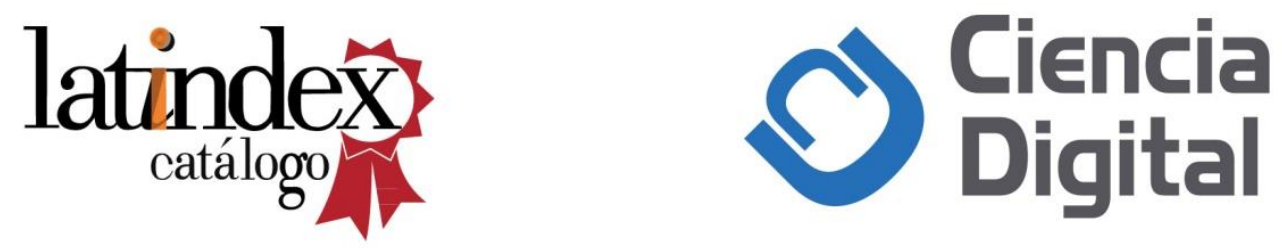